Doi: $10.15863 / \mathrm{TAS}$

International Scientific Journal

\section{Theoretical \& Applied Science}

p-ISSN: 2308-4944 (print) e-ISSN: 2409-0085 (online)

Year: $2014 \quad$ Issue: $11 \quad$ Volume: 19

Published: 30.11 .2014 http://www.T-Science.org
Dmitry Igorevich Khakhalin student of the 2 nd course

Financial University under the Government of the Russian Federation (Kaluga Branch) mitya.khakhalin@mail.ru

SECTION 31. Economic studies, Finance, innovation, risk management.

\title{
ENVIRONMENTAL PROTECTION AS AN INTEGRAL PART OF CORPORATE SOCIAL RESPONSIBILITY OF COMPANIES
}

Abstract: This article describes the theoretical foundations of corporate social responsibility and sphere of environmental protection as an integral part of the responsibility. This issue is at the forefront internationally, and this article presents a way of resolving problems impact on the environment.

Key words: corporate social responsibility, environmental protection, GAZPROM, LUKOIL, Sberbank.

Language: Russian

Citation: Khakhalin DI (2014) ENVIRONMENTAL PROTECTION AS AN INTEGRAL PART OF CORPORATE SOCIAL RESPONSIBILITY OF COMPANIES. ISJ Theoretical \& Applied Science 11 (19): 8892. doi: http://dx.doi.org/10.15863/TAS.2014.11.19.17

\section{ОХРАНА ОКРУЖАЮЩЕЙ СРЕДЫ КАК НЕОТЬЕМЛЕМАЯ ЧАСТЬ КОРПОРАТИВНОЙ СОЦИАЛЬНОЙ ОТВЕТСТВЕННОСТИ КОМПАНИИ}

Аннотация: В данной статье рассмотренны теоретические основы корпоративной социальной ответственности и сфера охраны окружающей среды как неотъемлемая часть ответственности. Именно эта проблема выходит на передний план в международном масштабе и в данной статье представлены некоторые пути разрешения проблем воздействия на окружающую среду.

Ключевые слова: Корпоративная сочиальная ответственность, охрана окружающей среды, ГАЗПРОМ, ЛУКОЙЛ, Сбербанк.

\section{Введение}

На сегодняшний день проблема корпоративной социальной ответственности бизнеса является одной из самых обсуждаемых в экономической среде. Немаловажными факторами для этого послужили возросшая роль бизнеса в развитии общества и повышение требования открытости ведения бизнеса. Однако не только общество нуждается в проведении каких-либо социальных действий от компаний, но и сами компании должны осознавать, что на сегодняшний день корпоративная социальная ответственность является одним из главных инструментов для повышения своей конкурентоспособности. За счет этого также можно добиться значительного повышения прибыли и репутации фирмы.

Данная проблема получила большое освещение среди ведущих экономистов и специалистов, таких как: А.Н. Аверин, С.В Братющенко, В.Е. Селиверстов, В.А. Дмитриев, А.Е. Костин. Их работы показывают процесс эволюции и распространения корпоративной социальной ответственности среди компаний нашей страны [4-6].

Для того чтобы понять, какую компанию можно называть социально ответственной, дадим определение корпоративной социальной ответственности и раскроем теоритическую составляющую нашей работы [7].

Корпоративная социальная ответственность - это принцип ведения бизнеса, который компания разрабатывает и формирует для себя на добровольной основе и реализует его для приобретения каких-либо экономических и репутационных преимуществ. Под данным определением понимается ответственность перед обществом за свои действия $\mathrm{c}$ точки зрения экологических принципов и стандартов, осуществления добросовестной деловой практики, создание крепких и гармоничных социально-трудовых отношений [7]. 
Корпоративную социальную ответственность можно разбить на несколько уровней [11].

Первый уровень корпоративной социальной ответственности, обычно, направлен выполнение прямых обязательств компании перед обществом и государство:

1. Выплаты заработной платы должными быть регулярными, а размер данных выплат должен иметь размер позволяющий нормальное воспроизводство рабочей силы;

2. Должно соблюдаться трудовое законодательство;

3. Должны соблюдаться установленные стандарты качества продукции и услуг, которые производить данная компания;

4. Полная и своевременная выплата всех налогов, которые должна оплачивать данная компания.

Второй уровень корпоративной социальной ответственности это - переход на новые уровни отношений между персоналом и непосредственным начальством внутри фирмы. Иными словами, на данном уровне социальной ответственности работник получает уверенность и гарантии в получении каких-либо льгот и услуг. Компания может предоставить данные гарантии за счет определенных социальных инвестиций. В свою очередь данные инвестиции можно разделить на 2 вида:

1. Инвестиции в человеческий капитал. Примером данных инвестиций могут служить: профессиональная подготовка, переподготовка к повышению квалификации персонала, совершенствование организации в плане охраны труда и здоровья работников.

2. Инвестиции, которые позволяют быть уверенными в повышении и гарантии пенсионного уровня работников, повышении качества и уровня жилищных условий и рекреационные социальные программы.

Последний, третий, уровень корпоративной социальной ответственности можно назвать территориальным, т.е. данные социальные

воздействия охватывают население территории, на которую может оказывать какое-либо положительное воздействие компания. Примером может служить вложения в развлекательную инфраструктуру, транспортную инфраструктуру региона, улучшение таких повседневных факторов как: освещенность улиц, благоустройство и содержание в порядке жилых и не только территорий [11].

Как было отмечено выше, корпоративная социальная ответственность является на сегодняшний день является одним из главных инструментов для повышения конкурентоспособности компании на рынке. Именно поэтому компаниям каждый день приходится доказывать своим покупателям и инвесторам свою состоятельность, доказывать то, что их производство экологически чистое. Это происходит путем составления отчетности в области корпоративной социальной ответственности и устойчивого развития.

Компании должны планировать свою деятельность исходя из подробного анализа, который показывает какое воздействие на окружающую среду будет оказано во время производства и просто функционирования компании.

Анализ деятельности компаний в области охраны окружающей среды

Одним из важнейших пунктов в графе «корпоративная социальная ответственность» каждой компании является охрана окружающей среды. Наиболее заинтересованы в поддержании благоприятных климатических и биологических условий компании, чья деятельность связана с добычей и обработкой полезных ископаемых.

На сегодняшний день инвестиции в охрану окружающей среды необходимы. В связи с изменчивым климатом и природными катаклизмами от компаний требуется помощь в самых различных формах: начиная с финансовых вложений и заканчивая созданием отрядов для перемещения их в зону бедствия. Данные о финансовых вложениях мы можем увидеть в таблице 1.

Таблица 1

Инвестиции в основной капитал, направленные на охрану окружающей среды и рациональное использование природных ресурсов в Российской Федерации (млн. руб., в фактически действовавших ценах) [8].

\begin{tabular}{|c|c|c|c|c|c|}
\hline & 2009 & 2010 & 2011 & 2012 & 2013 \\
\hline Всего вложений & 81914 & 89094 & 95662 & 116408 & 124050 \\
\hline из них на охрану: & & & & & \\
\hline атмосферного воздуха & 23242 & 26127 & 27882 & 34626 & 41196 \\
\hline водных ресурсов & 39219 & 46025 & 46610 & 52285 & 59807 \\
\hline земель & 11045 & 9340 & 13785 & 19888 & 13743 \\
\hline
\end{tabular}


Исходя из данных, указанных выше в таблице, мы можем сделать вывод, что для Российской Федерации свойственно ежегодное прибавление денежных средств в области охраны окружающей среды. Исходя из этого следует, что охрана окружающей среды как проблема международного уровня становится одной из важнейших в нашей стране.

Рассмотрим, на примере нескольких компаний, работающих в различных секторах экономики, способы охраны окружающей среды. Группа ЛУКОЙЛ Оверсиз осознает свою ответственность перед обществом по защите, сохранению благоприятной окружающей среды и рациональному использованию природных ресурсов. Исходя из информации на их официальном сайте, можно выделить основные в области промышленной безопасности и безопасности окружающей среды:

1. Достижение уровня промышленной и экологической безопасности, соответствующего наилучшим показателям ведущих нефтегазовых компаний мира;

2. Применение принципа «нулевого сброса» при разработке шельфовых месторождений в рамках установленных проектных решений;

3. Снижение техногенной нагрузки на окружающую среду от вновь вводимых объектов посредством улучшения качества подготовки предпроектной и проектной документации, проведения ведомственных экспертиз

Исходя из поставленных целей, группа ЛУКОЙЛ Оверсиз берет на себя следующие обязательства:

1. Осуществлять весь доступный и практически реализуемый комплекс мер по предупреждению аварий и смягчению их последствий

2. Проводить постоянную, целенаправленную работу по снижению потерь нефти, нефтепродуктов и газа и предотвращению поступления их в окружающую природную среду

3. Осуществлять оценку промышленных, профессиональных рисков и экологических аспектов, разработку и реализацию мер по их снижению, компенсации обусловленных ими потерь.

Исходя из полученных данных мы можем сделать следующие выводы относительно деятельности компании ЛУКОЙЛ. В связи с тем, что основной вид деятельности компании - это добыча и транспортировка полезных ископаемых - то существуют определенные риски того, что эти полезные ископаемые могут попасть в окружающую среду и нанести непоправимый ущерб биосфере нашей Земли. Что может сделать компания для предотвращения этих последствий
- это профилактические исследования загрязнения примыкающих зон и прогнозирование проблем, которые могут возникнуть в процессе деятельности компании [13].

Деятельность Группы «Газпром» связана с промышленным воздействием на окружающую среду, поэтому «Газпром» последовательно проводит работу по усилению внутрикорпоративной экологической политики. В целях обеспечения комплексного подхода и координации деятельности структурных подразделений ОАО «Газпром» в области охраны окружающей среды в октябре 2007 года создан постоянно действующий Координационный комитет ОАО «Газпром» по вопросам охраны окружающей среды.

Экологическая политика ОАО «Газпром» основана на Конституции Российской Федерации, федеральных законах и иных нормативных правовых актах Российской Федерации, международных договорах Российской Федерации в области охраны окружающей среды и рационального использования природных ресурсов.

Основным принципом деятельности компании является устойчивое развитие, под которым понимается динамичный экономический рост при максимально рациональном использовании природных ресурсов и сохранении благоприятной окружающей среды для будущих поколений. Именно поэтому, в целях реализации данного принципа компания принимает на себя следующие обязательства:

1. Осуществлять предупреждение загрязнений, что означает приоритет превентивных действий по недопущению негативных воздействий на окружающую среду перед действиями по борьбе с последствиями таких воздействий.

2. Учитывать интересы и права коренных малочисленных народов на ведение традиционного образа жизни и сохранение исконной среды обитания.

3. Обеспечивать широкую доступность экологической информации о хозяйственной деятельности ОАО «Газпром», прозрачность его природоохранной деятельности и принимаемых в этой области решений.

Исходя из представленных обязательств, ГАЗПРОМ использует следующие механизмы реализации экологической политики:

1. Внедрение и поддержание эффективной системы экологического менеджмента, основанной на требованиях международного стандарта ISO 14001;

2. Выделение достаточных организационных, материальных, кадровых и финансовых 
ресурсов для обеспечения выполнения принятых обязательств;

3. Учет экологических факторов при разработке политики закупок технологий, материалов и оборудования, выполнения работ и услуг подрядчиками;

4. Страхование высоких экологических рисков; Исходя из полученных данных мы можем сделать следующие выводы относительно деятельности компании ГАЗПРОМ. Также как и компания ЛУКОЙЛ, компания ГАЗПРОМ занимается добычей полезных ископаемых. Данный вид деятельности требует большого внимания от управляющей компании, так как необходимо не допустить утечек газа на объектах, так как это может нанести весомый урон атмосфере Земли. Также необходимо не забывать о нерушимом единстве всех составляющих окружающей среды, так как при открытии новых месторождений нужно быть достаточно осторожными и стараться не нарушать это единство [8].

Основными источниками воздействия Сбербанка на окружающую среду являются эксплуатируемые объекты инфраструктуры, расходные материалы, а также необходимые для осуществления нашей работы поездки на автотранспорте и перелеты на авиатранспорте. Для минимизации прямого негативного влияния на экологию группа осуществляет контроль за использованием ресурсов и реализует различные мероприятия по повышению ресурсо- и энергоэффективности. Снижая косвенное воздействие на окружающую среду, мы финансируем проекты в области альтернативной энергетики и повышения энергоэффективности. Кроме того, мы проводим экологические акции, направленные на продвижение бережного отношения к окружающей среде в обществе.

Сбербанк осуществляет контроль за использованием ресурсов с помощью построения системы управленческой отчетности, которая затрагивает такие аспекты, как образование отходов, потребление воды, выбросы парниковых газов и использование электрической и тепловой энергии.

Для достижения поставленных задач и целей реализуются следующие мероприятия:

1. Сокращение использования бумаги. Сбербанк Страхование внедрил централизованную систему управления печатью и сканированием документов. Благодаря отказу от бумажных носителей при пересылке, обработке и хранении страховой документации удалось значительно сократить расход бумаги. Каждый сотрудник теперь имеет возможность подсчитать в своем личном кабинете количество спасенных деревьев.

2. Раздельный сбор отходов. В 2013 году в офисах обслуживания Сбербанка Европа, Сбербанка Украина и ДенизБанка была произведена замена энергоемких неоновых элементов рекламных вывесок и указателей на светодиодные, что позволило существенно повысить световую отдачу при снижении энергопотребления.

3. Требования к эксплуатируемой оргтехнике. При закупках оргтехники и ІТ-оборудования для своих нужд ДенизБанк и Сбербанк Европа руководствуются определенными техническими критериями по энергоэффективности. В частности, все электронные устройства, закупаемые для нужд ДенизБанка, должны соответствовать классу энергопотребления $\mathrm{A}+$, а кондиционеры иметь необходимый инвертер.

Изучив направления реализации природоохранных проектов Сбербанка мы можем сделать следующие выводы. Чем деятельность банка может навредить окружающей среде? Так как банк работает с большим количеством бумаги, приоритетной целью должна являться минимизация использования данного ресурса в условиях работы в офисах. И именно поэтому Сбербанк успешно реализует программы для сокращения использования бумаги и переходу к использованию электронных ресурсов [9].

\section{Заключение}

Исходя из анализа реализации природоохранных программ 3-х крупных компаний Российской федерации можно сделать следующие выводы. Реализация экологической политики будет осуществляться посредством закрепления обязательств в определенных договорах между компанией и регионом в области охраны окружающей среды, в которых предполагается осуществление деятельности компании. Экологическая политика подлежит пересмотру, корректировке и совершенствованию при изменении приоритетов развития и условий деятельности компании [12].

Научное исследование проведено под руководством кандидата педагогических наук Александрова Евгения Леонидовича, Финансовый университет при Правительстве Российской Федерации (Калужский филиал). 


\section{References:}

1. Balynin IV (2013) Comprehensive assessment of socio-economic development of the Kaluga region. the World community: issues of socioeconomic, spiritual and political development of the Collection of scientific articles of the allRussian scientific-practical conference. Financial University under the Government of Russia (Novorossiysk branch); edited by L. C. Andrianova. Penza, pp. 289-298.

2. Balynin IV (2014) A comprehensive risk assessment model imbalance of subjects of the Russian Federation in the context of socioeconomic development of regions. Audit and financial analysis, No. 3, pp. 316-319

3. Dmitriev CA (2011) Corporate social responsibility. A new business philosophy: textbook. the allowance. Moscow: Vnesheconombank, 56.

4. Averin AN (2008) Social policy and social responsibility of the enterprise. - Moscow: alpha Press 2008;

5. Dmitriev CA (2011) Corporate social responsibility. A new business philosophy: textbook. the allowance. - Moscow: Vnesheconombank;

6. Peregudov S (2003) Corporations, state and society: the evolution of relations. - Moscow, Nauka.

7. Khakhalin DI, Alexandrov E (2014) L.Socially responsible behaviour of business in the Kaluga region: industry implementation, advantages and prospects. Actual problems of the theory and practice of economic development of the region. The collection of materials of the Interuniversity scientific-practical conference (Kaluga branch of the Financial University, may 15, 2014). Edited Pirogova T. E., Kuznetsova, A. A. - Kaluga: ID Eidos, pp. 431437.

8. (2014) Okhrana prirody. Ekologicheskaya politika. Available:

http://www.gazprom.ru/nature/ecology/ (accessed 29.11.2014)

9. (2014) Otchet o korporativnoy sotsial'noy otvetstvennosti. Available: http://report$\underline{\text { sberbank.ru/sr/environment/ (accessed }}$ 29.11.2014)

10. (2014) Ofitsial'naya statistika. Okruzhayushchaya sreda. Available:

http://www.gks.ru/wps/wcm/connect/rosstat_m ain/rosstat/ru/statistics/environment/\# (accessed 29.11.2014)

11.(2014) Korporativnaya sotsial'naya otvetstvennost'. Available: http://economicarggu.ru/2011 3/kivarina.pdf (accessed 29.11.2014)

12. (2014) Sotsial'naya otvetstvennost'. Available: http://ru.cocacola.co.il/category/QualityEnviron ment (accessed 29.11.2014)

13. (2014) Tseli kompanii v oblasti promyshlennoy bezopasnosti, okhrany truda i okruzhayushchey sredy. Available: http://lukoiloverseas.ru/social/index.php (accessed 29.11.2014) 